\title{
Hospital Services Quality And Its Relation With Patient Trust And Satisfaction
}

\author{
Hagar Mohammed Hassan1; Safaa Mohammed Abd Elrahman2;.Safaa Mohammed Zaki 3
}

\author{
1 B. Sc in Nursing, Minia University, Egypt. \\ 2 Assistant Professor of Nursing Administration, Faculty of Nursing - Minia Universit, Egypt . \\ 3Lecturer in psychiatric/Mental Health Nursing, Faculty of Nursing - Minia Universit, Egypt .
}

\section{Abstract}

Service quality is the expected benefits and control over the level of excellence to meet customer desires. Thus the service quality of health care is an effort to fulfill the needs and desires of the customer as well as the accuracy of delivery according to customer expectations. The service quality means the fulfillment of the patient's expectations, and a service provider ability in satisfying the patient's needs and expectations that will result in the customer's positive perception towards the capabilities of the service provider. The aim of the study: Assessing hospital services quality and its relation with patient trust and satisfaction. Research design: Descriptive correlational research design was used. Setting: This study was carried out at Mati Distract Hospital in Minia Governorate. Sample: Convenient sample of all available patients in Mati Hospital with total number $(n=100)$. Tools: Two tools were used, first tool demographic data, second tool consisted of (service quality, patient trust and patient satisfaction). Results: More than half (58\%) of patients assessed the service quality as moderate service. High percent $(57 \%)$ of patients had a moderate trust. More than half $(52 \%)$ of patients were dissatisfied. Conclusions: The majority of the patents were dissatisfied about the services provided by the hospital. There were statistical significance relation between (service quality, patient trust and patient satisfaction) and level of education. Recommendation: In service hospital training program for quality and quality management.

Keywords: Service quality/patient trust/patient satisfaction.

\section{Introduction:}

Service quality is a multidimensional concept that includes how far the difference between reality and expectations of customers for the services they received or acquired. Indeed, it is the expected benefits and control over the level of excellence to meet customer desires. Thus the service quality of health care is an effort to fulfill the needs and desires of the customer as well as the accuracy of delivery according to customer expectations. (1)

Service quality is an important element of customer responses as in the case of pure service, such as health care, financial services and education. If the services received or perceived as expected, then the perceived service quality is good and satisfactory. Conversely, if the services received are lower than expected, the quality of service perceived as poor quality. The quality of health care is multidimensional which consists of health care service users, health care providers and financial health care. (2)

Trust is one of the most important determinants of creating and maintaining sustainable long-term relationships between the provider and the customer in the services sector. In the health service, the trust is meant to be the belief of the patient to the practitioner or the hospital based on the concept that the care provider seeks the best for the patient and will provide the suitable care and treatment for him/her. (3)

Patient satisfaction is a feeling resulting from an evaluation process about what is received on what to expect including the purchase decision of the goods itself, as well as the needs and desires associated with the purchase. Customers have level of satisfaction and dissatisfaction after having or experiencing each service according to how far their expectation fulfilled or exceeded. Expectation is an internal standard used by customer to judge a quality of service experience (4). Dissatisfaction of customer with the service occurs due to the following causes: there is a gap between expectation and reality, poor service, bad behavior of personnel, unsupportive physical atmosphere and condition and too expensive cost. (5)

Patient satisfaction with medical care is a multidimensional concept, with a dimension that corresponds to the major characteristics of providers and services. Within the health care hospital, patient satisfaction can be considered as an important component and measure of the quality of care. Patient satisfaction is a cumulative construct which embraces satisfaction with various hospital facilities such as technical, functional, interaction and atmosphere. Patient satisfaction plays an important role in the continuity of service utilization and positively influences the patient's trust. (6)

The service quality means the fulfillment of the patient's expectations, and the ability of a service provider in satisfying the patient's needs and expectations will result in the patient's positive perception towards the capabilities of the service provider. When the perception of service quality is positive and the performance of the provider results in meeting patient's expectations, the patients will be satisfied and trust more in the provider's capabilities and competencies. In contrast, if the service provider's performance is accompanied by low quality and failure in satisfying the customer's expectations, the customer's trust in competencies and capabilities of the service provider will decrease. In fact, when a customer trusts in an organization, he/she trusts to the quality of its goods and services. (7)

\section{Significance of the study:}

Hospitals provide the health services to the citizens in their daily life. This shows the importance of hospitals 
and their role in providing better health care services to the citizens. It has under gone many changes in technology as well as in terms needs and demands of patients. It identifies these needs and brings changes to satisfy patients. Trust is especially important in health care service organizations because it creates the environment in which patient disclosures and cooperates in treatment, desires of seeking care, making easier to adjust unhealthy behavior as well as minimize the chance of complaints, disputes and lawsuits. For this purpose the researcher decided to study hospital services quality and its relation with patient trust and satisfaction.

\section{Aim of the study:}

The aim of this study is to assess hospital services quality and its relation with patient trust and satisfaction at Mati Distract Hospital in Minia Governorate.

\section{Research Question:}

Is there is a relation between hospital services quality, patient trust and satisfaction?

\section{Subjects and Methods}

\section{Research design:}

Descriptive correlational research design was utilized in current study to achieve the aim of the study.

\section{Setting:}

Governorate.

The study was conducted at Mati Hospital in Minia

\section{Subject:}

Convenient sample of all available patients in a selected Hospital in Minia Governorate was utilized in the current study, with total number $(n=100)$.

\section{Tools of data collection:}

following tools

Data for this study was collected by using the

It divided into two parts, it include:-

1st part: -Socio- Demographic data sheet:

To get information about the patient it includes (Sex, Age, Educational status, Family status and Department)

2nd part: - tools.

\section{1-Service quality scale:}

Service quality scale adopted from (Zineldin (2006) (8) \& Parasuraman (1994) (9)) and necessary modification was made by the researcher. It includes 20 questions to measure service quality in the hospital. The question was ranked from (1) low to (3) high. With scoring system ranging from (20) to (33) low. From (34) to (46) average. From (47) to (60) high.

\section{2- Patient trust scale}

Patient trust scale adopted from (Hall et al (2002) (10) \& Alrubaiee (2010) (11)) and necessary modification was made by the researcher. It includes 17 questions to measure patient trust. The questions were ranked from (1) low to (3) high. With scoring system: From (17) to (28) disagree. From (29) to (39) neither. From (40) to (51) agree.

\section{3-Patient satisfaction scale:}

Patient satisfaction scale adopted from (Grogan et al (1995) (12)). It includes 14 questions to measure the level of patient satisfaction. The questions ranked from (1) disagree to (2) agree. With scoring system includes: From (14) to (21) dissatisfied (disagree). From (22) to (28) satisfied (agree).

\section{Validity:}

The tool was tested for content validity by a jury of experts in the field of the study.

\section{Reliability:}

Cronbach's alpha for reliability testing internal consistency was performed for assessment knowledge , attitude and resources toward needle stick injury it was $(0.96,0.71$ and 0.68$)$ respectively .

\section{Pilot study:}

A pilot study was carried out on approximately (10 $\%$ ) of the study sample(10 patient) in a selecting setting to evaluate the validity and reliability of the study tool and to estimate the time needed for filling the tool that ranged between 15 to 20 minute. As well as, identifying problems that may be encountered during actual data collection.

\section{Study procedure:}

An official letter of the study approved was obtained from Dean of Faculty of Nursing -Minia University to the manager of the hospital. This letter was including a brief explanation of the objective of the study. After receiving the initial acceptance from the ethical committee at the Faculty of Nursing, Minia University, the researcher initially introduced herself to all participants to explain the aim of the study and to obtain their permission. They were assured that the collected data would be absolutely confidential. Data were collected in the period from 1 May 2016 until 30 October 2016. The researcher collected the data at the morning at two days/week (Saturday and Monday) from 10 AM to 12 PM.

\section{Ethical consideration:}

A written initial approval obtained from the research ethical committee in the Faculty of Nursing, Dean of Nursing Faculty and agreement from Egypt academic for research center and technology. Participants in this study were voluntary and informed about the purpose, procedure of the study and the right to withdraw from the study at any time without any rational. Written consent was obtained from the subjects after reading all details. Confidentiality and anonymity of each subject were ensured through coding of all data and protecting the obtained data. 


\section{Statistical design:}

Data entry and statistical analysis were done using a Statistical Package for Social Science (SPSS). Data were presented using descriptive statistics in the form of frequencies and percentages, mean and standard deviations. Probability ( $p$-value) is the degree of significance, if it less than 0.05 was considered significance and correlation coefficient was done by using Spearman rank correlation.

\section{Results:}

Table (1): Frequency distribution of personal data among the studied patients $(n=100)$ :

\begin{tabular}{|l|l|l|}
\hline Data & No & $\%$ \\
\hline Sex & 42 & \\
Male & 58 & $42 \%$ \\
& & $58 \%$ \\
\hline Age & & \\
$\leq 20 y$ & 11 & $11 \%$ \\
$21-40 y$ & 37 & $37 \%$ \\
$41-50 y$ & 34 & $34 \%$ \\
$\geq 51 y$ & 18 & $18 \%$ \\
\hline Education & & \\
Secondary & 42 & $42 \%$ \\
University & 21 & $21 \%$ \\
Post graduate & 1 & $1 \%$ \\
Illiterate & 36 & $36 \%$ \\
\hline Marital status & & $14 \%$ \\
Single & 14 & $70 \%$ \\
Married & 70 & $12 \%$ \\
Widow & 12 & $4 \%$ \\
Divorced & 4 & $25 \%$ \\
\hline Department & 25 & \\
Medical & & \\
Surgical & & \\
Obstetric & & \\
\hline (58\%) of the & \\
\hline
\end{tabular}

Table (1) shows that, (58\%) of the studied subjects were females, $(42 \%)$ were males, $(42 \%)$ had secondary education, (70\%) were married and (46\%) of them admitted at surgical department.

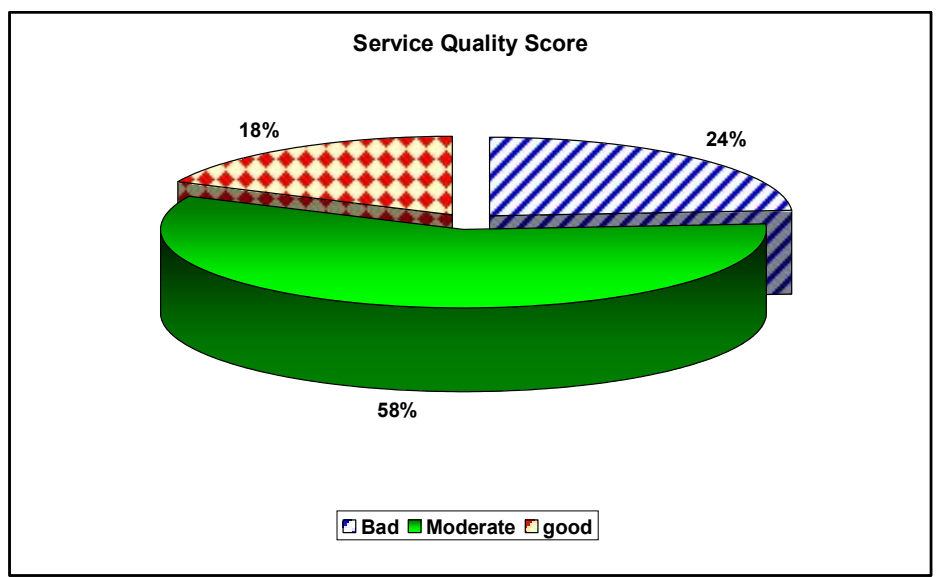

Figure (1): Frequency distribution of total score among service quality of the studied patient $(n=100)$ :

Figure (1) shows that $58 \%$ of patients evaluated the service quality as moderate service, $24 \%$ of them evaluated as low service and $18 \%$ of them evaluated as high service. 


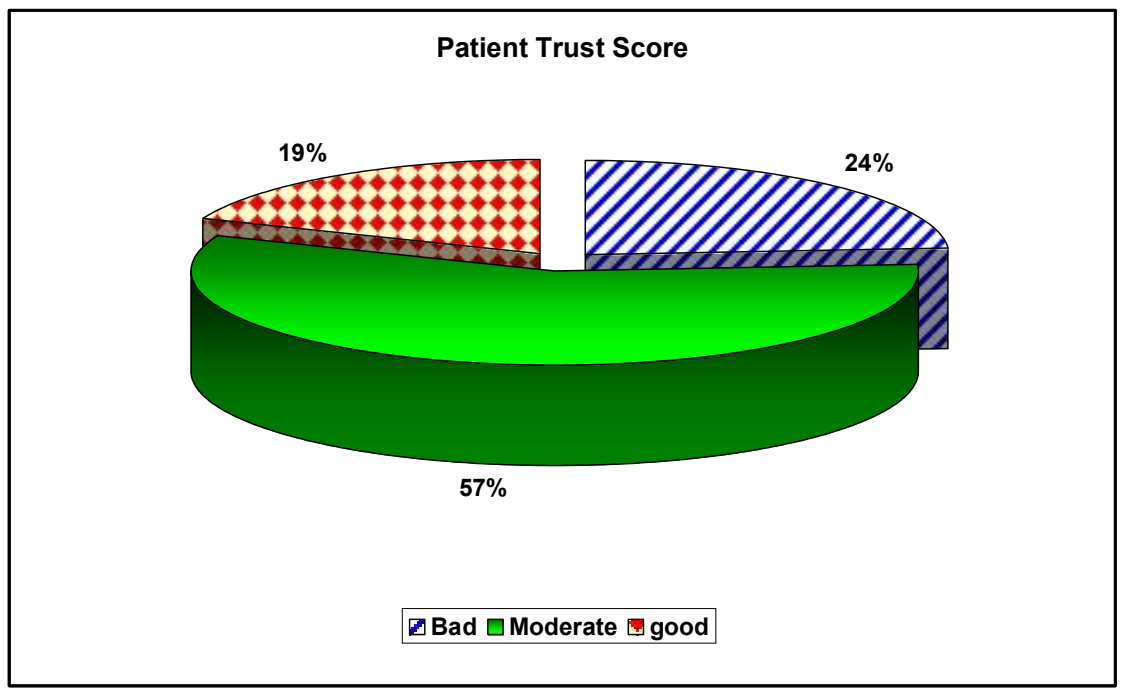

Figure (2): Frequency distribution of total score among patient trust of the studied patient (n=100):

Figure (2) illustrates that $57 \%$ of patients had a moderate trust, $24 \%$ had a low trust and $18 \%$ of them had a high trust.

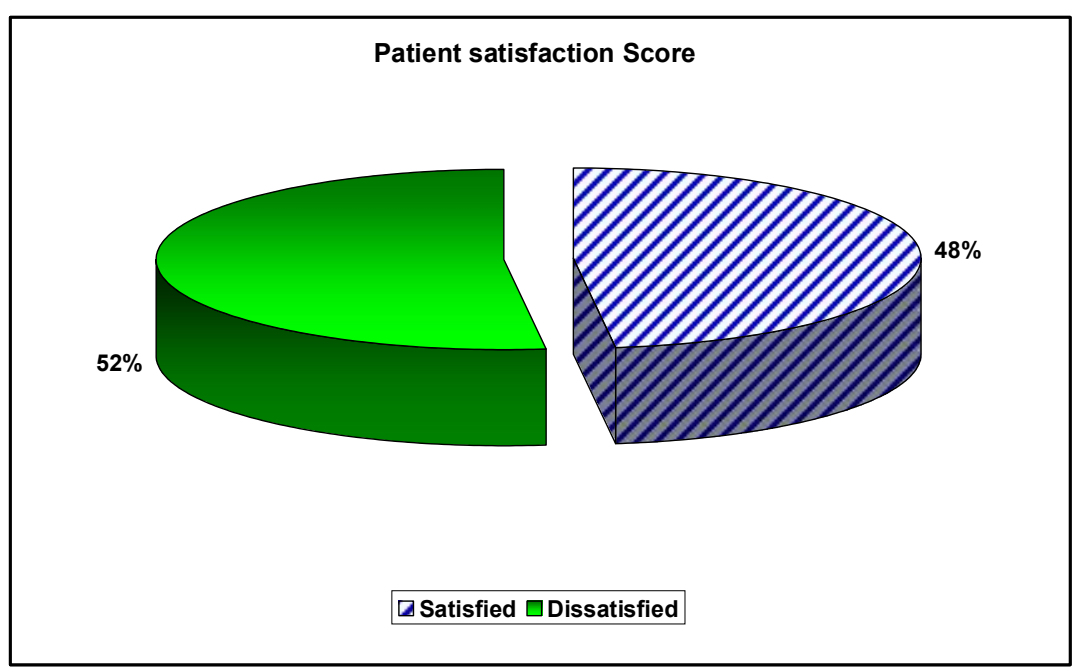

Figure (3): Frequency distribution of patient satisfaction score of studied patients $(n=100)$ :

Figure (3) demonstrates that $52 \%$ of patients were dissatisfied while $48 \%$ of them were satisfied.

Table (2): Relation between personal characteristics with (hospital service quality, patient trust\& patient satisfaction)

\begin{tabular}{|l|l|l|l|}
\hline \multirow{2}{*}{ Data } & \multicolumn{1}{|c|}{ Service quality } & \multicolumn{1}{c|}{ Patient trust } & \multicolumn{1}{c|}{ Patient satisfaction } \\
\cline { 2 - 4 } & \multicolumn{1}{|c|}{ Mean \pm SD } & \multicolumn{1}{c|}{ Mean \pm SD } & \multicolumn{1}{c|}{ Mean \pm SD } \\
\hline Age & & & $21.2 \pm 3.4$ \\
$\leq 20$ years & $40 \pm 9.4$ & $34 \pm 7.6$ & $21.5 \pm 4.1$ \\
21-40years & $38.8 \pm 8.1$ & $33.6 \pm 7.3$ & $22.5 \pm 3.9$ \\
41-50years & $40.4 \pm 6.9$ & $33.9 \pm 5.5$ & $19.9 \pm 3.7$ \\
$\geq 51$ years & $40.2 \pm 7.6$ & $32.2 \pm 6.04$ & 1.7 \\
\hline F-Test & 0.2 & 0.3 & $0.02^{*}$ \\
\hline $\mathrm{p}$ & 0.8 & 0.8 & $20.7 \pm 3.7$ \\
\hline Sex & & $33.7 \pm 6.02$ & $22.1 \pm 4.1$ \\
Male & $40.1 \pm 7.5$ & $33.3 \pm 6.9$ & \\
Female & $39.5 \pm 8.2$ & &
\end{tabular}




\begin{tabular}{|l|l|l|l|}
\hline \multirow{2}{*}{ Data } & \multicolumn{1}{|c|}{ Service quality } & \multicolumn{1}{c|}{ Patient trust } & \multicolumn{1}{c|}{ Patient satisfaction } \\
\cline { 2 - 4 } & \multicolumn{1}{|c|}{ Mean \pm SD } & \multicolumn{1}{c|}{ Mean \pm SD } & \multicolumn{1}{c|}{ Mean \pm SD } \\
\hline T-Test & 0.1 & 0.09 & 0.03 \\
\hline P & 0.7 & 0.7 & 3.08 \\
\hline Education & & $31.5 \pm 6.8$ & $21.1 \pm 4.5$ \\
Secondary & $37.5 \pm 7.4$ & $36.7 \pm 5.9$ & $22.2 \pm 3.1$ \\
University & $42.5 \pm 8.5$ & $45.4 \pm 4.6$ & $27.6 \pm 3.5$ \\
Post graduate & $55.3 \pm 6.4$ & $33.5 \pm 5.5$ & $21.5 \pm 3.8$ \\
Illiterate & $40.2 \pm 6.8$ & 4.3 & 1.05 \\
\hline F-Test & 3.6 & $0.007^{*}$ & 0.3 \\
\hline P & $0.01^{*}$ & & \\
\hline Marital status & & $37.2 \pm 4.9$ & $22.5 \pm 2.8$ \\
Single & $40.4 \pm 8.05$ & $32.8 \pm 6.9$ & $21.4 \pm 4.2$ \\
Married & $39.9 \pm 7.8$ & $32.9 \pm 5.4$ & $20.5 \pm 3.4$ \\
Widow & $39.1 \pm 7.1$ & $33.5 \pm 1.7$ & $25 \pm 3.4$ \\
Divorced & $37 \pm 9.2$ & 1.8 & 1.6 \\
\hline F-Test & 0.2 & 0.1 & 0.1 \\
\hline P & 0.8 & $33.7 \pm 6.5$ & $20.6 \pm 3.9$ \\
\hline Department & & $32.7 \pm 6.1$ & $21.8 \pm 3.9$ \\
Medical & $40.9 \pm 0.8$ & $34.6 \pm 7.1$ & $22.2 \pm 4.1$ \\
Surgical & $38.1 \pm 6.9$ & 0.6 & 1.1 \\
Obstetric & $41.4 \pm 8$ & 0.5 & 0.3 \\
\hline F-Test & 2.02 & & \\
\hline P & 0.1 & & \\
\hline & & & \\
\hline
\end{tabular}

Table (2) shows the difference between demographic characteristics and (hospital service quality, patient trust\& Patient satisfaction). It was noticed that a positive significant relation between age and patient satisfaction and level of education with service quality and patient trust.

Table (3): Correlation matrix between service quality, patient trust and patient satisfaction:

\begin{tabular}{|c|c|c|c|c|}
\hline \multicolumn{2}{|c|}{} & Service quality & Patient trust & Patient satisfaction \\
\hline \multirow{2}{*}{ Service quality } & $\mathrm{r}$ & 1 & 0.736 & 0.53 \\
\cline { 2 - 5 } & $\mathrm{p}$ & & $0.0001^{*}$ & $0.0001^{*}$ \\
\hline \multirow{2}{*}{ Patient trust } & $\mathrm{r}$ & & 1 & $0.0001^{*}$ \\
\cline { 2 - 5 } & $\mathrm{p}$ & & & 1 \\
\hline \multirow{2}{*}{ Patient satisfaction Score } & $\mathrm{r}$ & & & \\
\cline { 2 - 5 } & $\mathrm{p}$ & & & \\
\hline
\end{tabular}

Table (3) shows that, there is a highly significant positive correlation between service quality, patient trust $\left(\mathrm{p}=0.0001^{*}\right)$ and patient satisfaction $\left(\mathrm{p}=0.0001^{*}\right)$.

\section{Discussion:}

The aim of this study was to assess hospital services quality and its relation with patient's trust and satisfaction. Modern literature states that the patient's satisfaction has a positive relationship with quality of services, so service quality can positively affect the patient's satisfaction. At the same time patient's satisfaction can help to measure the quality of health services provided by the hospital.

Concerning the personal characteristics of the studied patient, the current study results revealed that, half of the patient's ages were ranged between $21-40$ years, $58 \%$ $P$ a g e |101 of the subjects were females, $42 \%$ were graduated from secondary school and two thirds of them were married and admitted in surgical department. This is nearly consistent with the results of Sayed 2012 (13) who found that, half of the patient's ages were ranged between 25-40 years, the majority of them were females $(57 \%)$ and more than two thirds of them were married.

The current study result is inconsistent with Soolakshna 2010 (14) who found the age of the sample was ranged between $30-50$ years, $77 \%$ of the sample was males and approximately $67 \%$ have their highest level of education. 
The present study result also found that, $58 \%$ of patients had a moderate degree of service quality score, $24 \%$ of them evaluated the service quality as low level and only $18 \%$ of them evaluated the service quality as high level. This can be possibly attributed to the following cause's low of resources and facilities, shortage of staff, lack of medical skills, patients waiting time while receiving care was long and their expectations were not meet.

The current study are consistent with the findings of Shams 2012(15) who reported that, $(51.5 \%)$ of the sample assessed the service as low level, (5\%) assessed it as high and $(43.6 \%)$ were neutral.

The current study are also inconsistent with the findings of Sima Marzban 2015(16) who stated that the majority of the samples were highly satisfied with the quality of services they received. This can be due to the staff are highly qualified, available, sufficient and disciplined, more facilities and resources, the cost of the services are reasonable and waiting time for medication and tests are speed.

The current study found that, $57 \%$ of patient had a moderate level of patient trust, $24 \%$ had low level while $19 \%$ had high level of patient trust, this can be explained by the gap between the staff and the patient, the staff didn't able to meet the needs and expectations of the patient, not prepared well to maintain on the patient privacy, not able to handle the patient problem and the staff didn't provide the patient with all necessary information concerning with the illness and the treatment.

In the same aspect, the current study are consistent with Sayed 2012(17) who stated that $58.4 \%$ of patient had a neutral level of patient trust, 35.6 had bad level of patient trust while only $5.9 \%$ of them had good level of patient trust.

In the current study, it also observed that the level of patient satisfaction with hospital service quality is low in Matay Distract hospital, about $52 \%$ of respondents were dissatisfied with their hospital service quality and $48 \%$ of them were satisfied. This can be caused by low facilities and resources, shortage of staff and the staff was not prepared well. These results are consistent with result of Sayed $2012(18)$ who stated that only $7.9 \%$ of the sample was very satisfied, $54.5 \%$ were satisfied and $37.6 \%$ were neutral.

The findings of the study carried out by Marinkovic (2013) (19) in Serbia are inconsistent with the current result as the majority of the sample was highly satisfied with the quality of services they received $(85 \%)$, this is due to fast response to the patient's request for assistance or relief of pain, this is the most important factor influencing the patient's satisfaction. Fast service delivering was the second important factor in the patient satisfaction.

In the present study, it was observed that, the highest total mean score for service quality, patient trust and satisfaction was in post graduate and in obstetric department, this can be explained by highly-educated patients, had open mind, able to judge on quality of service correctly. Mean score of patient satisfaction was slightly high among females than males $(22.1+4.1)$, in old age than young $(22.5+3.9)$, in post graduate than illiterate $(27.6+3.5)$. In contrast, the current study result are inconsistent with Ehsan Zarei 2015(20) who stated that, the overall satisfaction's mean scores in terms of demographic variables of patient like (age, length of stay, gender and education level ) had no effect in the patient satisfaction.

The findings of current study showed that, there is a positive correlation was found between service quality and patient's trust $(\mathrm{p}=0.001 *)$, this can be interpreted as; the patient's experience of the services provided by the hospitals has a strong impact on the outcome variables such as patient's trust. In the same context, results of Moliner's 2010(21) study in Spain showed that hospital's service quality is the most important determinant of the patient's trust. Chang et al 2013(22) in their study on Taiwan's hospitals showed that "service quality" perception has a strong positive impact on the patient's trust.

In deed the present study found that, there is a positive correlation was found between service quality and patient's satisfaction $(\mathrm{p}=0.001 *)$. Because there are many factors affecting patient's satisfaction i.e. the length of patient waiting time, listening to them and their relatives carefully, maintaining on the privacy and dignity of the patient, the cleaning and safety of the work environment.

In this respect Areiqat, \& Tailakh 2012(23) regarding the relationship between service quality and patient's satisfaction, they found that, there is a positive correlation was found between service quality and patient's satisfaction. There are many factors affecting patient's satisfaction i.e. humility of nurses, nurses ability to respect their family members, listening to patients and relative carefully. Besides this the work environment of nurses and the staffing ratio of nurses and patients also play an important role in patient's satisfaction.

\section{Conclusion:}

Based on the finding of this current study, it was concluded that:

The majority of the patents were dissatisfied about the services provided by the hospital. There were statistical significance relation between (service quality, patient trust and patient satisfaction) and level of education.

\section{Recommendations:}

Based on results of the present study the following can be recommended:

In service hospital training program for quality and quality management in Mati hospital.

\section{Reference}

[1]. Tjiptono, F., Chandra, G. (2016): Service quality dan satisfaction. Yogyakarta: Penerbit Andi

[2]. Deng Z, Lu Y, Wei KK, Zhang J (2010): Understanding customer satisfaction and loyalty: An empirical study of mobile instant messages in China. Int J Inf Manag; 30(4):289-300.

[3]. Grondahl, V.A., Hall-Lord, M.L., Karlsson, I., Appelgren, J., Wilde-Larsson, B, (2013): Exploring patient satisfaction predictors in relation to a theoretical model. International Journal of Health Care Quality Assurance, 25(1), 37-54. 
[4]. Abdul. M. A., Habib. A. and Rafiqul I. C (2011): Factors influencing patient satisfaction in primary healthcare clinics in Kuwait. International Journal of Health Care Quality Assurance. Vol. 24 Iss: 3, pp. $249-262$.

[5]. Alkaa'ida, F (2011): The mediating effect of patient satisfaction in the patients' perceptions of healthcare quality - patient trust relationship.International Journal of Marketing Studies. Vol. 3, No.

[6]. Zineldin, M (2006): The quality of health care and patient International journal of health care quality assurance. 19 (1), 60-92

[7]. Juhana, D., Manik, E., Febrinella, C., Sidharta, (2015): Empirical study on patient satisfaction and patient loyalty on public hospital in Bandung, Indonesia. International Journal of Applied Business and Economic Research, 13(6), 43054326.

[8]. Zineldin, M (2006): The quality of health care and patient International journal of health care quality assurance. 19 (1), 60-92

[9]. Parasuraman, A., Zeithaml, V. \& Berry, L. (1994): Reassessment of expectations as a comparison standard in measuring consumer perceptions of service quality: implications for future research. Journal of Marketing, 58 (1), 11-24.

[10]. Hall, M. A., Zheng, B., Dugan E., Camacho, F., Kidd, K.E., Mishra, A. \& Balkrishnan,R (2002): Measuring Patient trust in their primary care provider. Medical care research and review, 59 (3), 293-318.

[11]. Alrubaiee L, Alkaa'ida F (2010): The mediating effect of patient satisfaction in the patients' perceptions of healthcare quality-patient trust relationship. Int J Marketing Stud. 3(1):103-27.

[12]. Grogan S,Conner M,Willities D et al (1995): Development of questionnaire to measure patient satisfaction with general practioners services. $\mathrm{Br}$ FGen pract 45:524
[13]. Sayed,N, Perunjodi, N,et al (2012): The relationship between demographic data of the studies patients. International Journal of Service Industry Management, 9 155-168.

[14]. Soolakshna D. Lukea-Bhiwajee, University of Technology, Mauritius (2010): Service Quality in the public service. International jornal of management and marketing research. Volume 3. Number 1.

[15]. Shams, Ur, Rehman (2012): Patient satisfaction regarding hospital services: A study of Umea Hospital.

[16]. Sima Marzban (2015): An empirical study of the impact of service quality on patient satisfaction in Iran Hospitals. Article in Global journal of health science .

[17]. Sayed, Nasir, Hussain (2012).:Patient satisfaction regarding hospital services: A study of Umea Hospital.

[18]. Sayed, Nasir, Hussain (2012).:Patient satisfaction regarding hospital services: A study of Umea Hospital.

[19]. Senić, V \& Marinković, V (2013): Patient care, satisfaction and service quality in health care. International Journal of Consumer Studie. 37(3), 312-319.

[20]. Ehsan Zarei (2015): An empirical study of the impact of service quality on patient satisfaction in Iran Hospitals.

[21]. Moliner, M, A (2010): Loyalty perceived value and relationship quality in healthcare services. J Serv Manag. 20(1):76-97.

[22]. Chang CS, Chen SY, Lan YT (2013): Service quality, trust, and patient satisfaction in interpersonal-based medical service encounters. BMC Health Serv Res. 13:22.

[23]. Areiqat \& Tailakh (2012): The impact of hospital brand image on service quality, patient satisfaction and loyalty. Afri Zamil, can Journal of Business Management, 5(12), 4873-4882. 